\title{
Contraception Options and Provision to Adolescents
}

Cynthia L. Robbins, MD MS ${ }^{1}$ and Mary A. Ott, MD MA ${ }^{2}$

\author{
${ }^{1}$ Assistant Professor of Clinical Pediatrics, Section of Adolescent Medicine, Department \\ of Pediatrics, Indiana University School of Medicine \\ ${ }^{2}$ Associate Professor of Pediatrics, Section of Adolescent Medicine, Department of \\ Pediatrics, Indiana University School of Medicine
}

Corresponding Author:

Cynthia L. Robbins, MD MS

$410 \mathrm{~W} 10^{\text {th }}$ Street HS 1001

Indianapolis, IN 46205

cyrobbin@iu.edu

\section{Word Count:}

Key words: Contraception, adolescent, counseling, intrauterine device, contraceptive implant, pregnancy prevention Short Title: Contraception for Adolescents

This is the author's manuscript of the article published in final edited form as: 


\begin{abstract}
Adolescent pregnancy is a significant cause of global morbidity and mortality.

Adolescents who become pregnancy have lower educational attainment, are more likely to live in poverty, and have lower wellbeing. Increasing access to hormonal contraceptives and long acting reversible contraception is highly effective in reducing adolescent pregnancies. This narrative review covers key aspects of the provision of contraception to adolescents, including confidentiality, counseling, and data supporting expanded access to adolescents. We provide information for pediatric providers to start adolescent patients on contraceptives, including a detailed description of each method, including effectiveness, use, starting, side effects and benefits. Tools for counseling and prescribing are provided.
\end{abstract}




\section{Introduction}

The Problem of Adolescent Pregnancy

Although adolescents have many options for effective contraception, adolescent pregnancy continues to be a significant cause of morbidity and mortality worldwise. Approximately sixteen million teens worldwide became pregnant in 2014. ${ }^{1}$ Many disparities exist; $95 \%$ of pregnancies among adolescents occur in low and middle income countries. In low income countries, pregnancy can be the result of early marriage, sexual coercion, or abuse. ${ }^{2}$ In the United States, which has one of the highest teen pregnancy rates in developed countries, ${ }^{3}$ large ethnic and geographical differences exist. American teens who are Hispanic or black have higher pregnancy rates than non-Hispanic whites, and pregnancy rates are much higher in some states (southern and southwestern states) than in other areas of the country. These differences likely represent larger socioeconomic disadvantages. ${ }^{4}$ Pregnancy during adolescence can have lifelong health and socioeconomic effects: in the U.S., only $2 \%$ of adolescent mothers go on to graduate from college and are less likely to graduate high school than their peers. ${ }^{5}$ Worldwide, lower scholastic achievement is also seen, along with pregnancy complications representing the leading cause of death in 15-19 year olds in low and middle income countries. ${ }^{1}$

\section{Effectiveness of Contraception}

Effective contraception lowers adolescent pregnancy rates, with the greatest declines occurring when adolescents have easy access to long acting reversible contraceptives. ${ }^{6,7}$ This relationship between access to effective contraceptives and adolescent pregnancies can been seen on a population level. For example, the United States has seen a drop in adolescent pregnancy, birth, and abortion rates, although rates of sexual activity have not changed among American teens, ${ }^{8}$ with much of the decline among adolescents can be attributed to improved contraception use. ${ }^{9}$ In addition to preventing unplanned pregnancy, contraceptives can have medical benefits for teens, such as dysmenorrhea management, limiting menstrual blood loss, and acne treatment. Contraceptives today are safe, and clear guidance for prescribing and use in patients with medical conditions 
are readily available to providers. ${ }^{10}$ This narrative review highlights best practices and new developments in the provision of highly effective LARCs and hormonal contraceptives to adolescents. Information on barrier methods and less effective methods such as periodic abstinence can be found elsewhere. ${ }^{11}$

\section{Counseling and Starting Contraception}

\section{Confidentiality}

In the setting of contraceptive provision, confidentiality involves allowing the adolescent to control who has access to their sexual health information. For adolescents, confidentiality is a cornerstone to effective contraceptive counseling. ${ }^{13,14}$ Questions regarding sexual behavior, sexually transmitted infections, and contraception should always be asked confidentially; Policies limiting confidentiality have been associated with less willingness of teens to disclose and less access to family planning services, leading to higher pregnancy rates. ${ }^{15.16,17,18}$. As a result, maintaining confidentiality is a critical piece when working with adolescents. ${ }^{17,18,19,20}$

\section{Human Rights and Adolescent Sexual Health}

The Convention on the Rights of the Child identifies access to sexual and reproductive health information and services as a basic human right for adolescents. The Convention states that adolescents themselves are considered active rights holders, and should be allowed to progressively exercise these rights with their evolving capacity. As part of an adolescent's right to the highest attainable health is the right to sexual and reproductive health information and services, including contraception and safe abortion. ${ }^{21}$

\section{Role of Parents}

While adolescents have rights to confidentiality, it can often be helpful to involve a parent or another trusted adult in sexual health decisions. Parents play an important and often under-appreciated role in communicating with their child about sex and facilitating access to sexual health services. ${ }^{22}$ Parental communication and support is associated with a delayed onset of sex, and safer sex behaviors. ${ }^{23,24}$ As long as the adolescent feels 
comfortable and safe, we encourage adolescents to talk to a parent or other trusted adult about sex and sexual health decisions. Human rights documents recommend a shift in parents' roles for adolescents from that of decision-maker and caregiver to the provision of direction, guidance, and a safe environment, while taking into account the adolescents' views. ${ }^{24}$

\section{Start asking about sexual behavior early}

Most adolescents initiate sexual activity between the ages of $15-19 .{ }^{2,28}$ Because of the enormous developmental chances across adolescence, interviews about sexual behavior and pregnancy prevention must be sensitive to developmental age and ensure confidentiality about the conversation. There is no specific age to start this conversation. Instead it should represent a continuum of conversations about sexuality and sexual development. For example, school aged children should be taught personal safety and appropriate names for body parts and as they age, this conversation shifts to also include sexual behavior.

\section{Counseling approaches}

Motivational interviewing (MI) allows counseling to be done in a non-judgemental, caring and patient-centered manner ${ }^{29}$ Open ended questions and other motivational interviewing (MI) approaches allow providers to explore knowledge of pregnancy risks, sexually transmitted infection prevention, and generally attitudes towards sex.

Interventions using MI have been shown to improve sexual health outcomes. ${ }^{30} \mathrm{MI}$ allows providers to engage adolescents in the conversation and give them control of the medical decision making about their reproductive health needs (Box 1.). Teens who are not yet sexually active should be encouraged to delay sex, be assessed for future sexual behaviors, and be provided with information and contraception (if indicated) to meet anticipated sexual health needs. Services available at your office, the patient's working knowledge of contraception, and reproductive health resources should be discussed to foster health promoting behaviors should their decisions around sex change. Guidelines for general reproductive health interviews allow providers to obtain the necessary information to guide counseling and provision of services for pregnancy and sexually 
transmitted infection (STI) prevention. One example is the U.S. Centers for Disease Control and Prevention (CDC) interview structured around "5 Ps": partners, prevention of pregnancy, protection from STIs, sexual practice, and past history of pregnancy and STI; example questions are available on their website. ${ }^{31}$

Adolescents have wide developmental variation in sexual health, knowledge, behaviors, attitudes and access to services. Providers will need to assess what adolescents know about various forms of contraception, and the sources of that information (sexuality education programs, family, friends, internet searches). Research suggests that families, friends and partners are strong influences on the uptake and choice of contraceptive methods, as a result an assessment of family and friends' experiences is often is a good place to start. ${ }^{32,33}$ Myths about contraceptives, such as the shot makes you infertile, should be addressed and acknowledged. Side effects should be discussed however, reassured at the same time that you, the provider, are there should they occur. Benefits should also be highlighted.

Websites designed for teens on contraception can be helpful aids in going through methods and also provide orientation to resources available for home research, or to help your patient discuss with their parents (if desired). Additionally, resources on contraception should be part of the display of information available in waiting rooms. Side effects should be discussed however, reassured at the same time that you the provider are there should they occur. All contraceptives will have some impact on menstruation and views on this impact explored. Additionally, knowledge of how teens experience their periods should be considered in counseling. For example, teens with dysmenorrhea or menorrhagia can see benefits on pain and flow with some contraceptives, but these symptoms may worsen on others.

\section{Guidelines for Pediatricians}

Current guidelines and best practices for the provision of contraception include the Medical Eligibility Criteria (MEC) and Selected Practice Recommendations (SPR) available from the World Health Organization (WHO) and U.S. CDC(see Box 2). ${ }^{10,11,12}$ 
While these resources are for all women, adolescent-focused recommendations are included when they differ from adult recommendations. The SPR emphasizes a woman's choice and self-determination, and gives guidance on use and side effect management of all contraceptive options. While contraceptives are very safe for most patients, they are medications and devices, and individuals some medical conditions may be at higher risks for side effects and complications. The U.S. Medical Eligibility Criteria and the WHO Medical Eligibility Criteria are both available resources for providers to assist and assessing potential risks. ${ }^{10,11}$ These guidelines categorize risk by degree of risk and potential benefit. This review will identify MEC Category 4 medical conditions (do not use under any circumstances) as contraindications, and MEC Category 3 medical conditions (risks generally outweigh benefits, but can be individualized to patient and used with caution) as use with caution.

Best practice guidelines recommend starting counseling with the most effective method first, followed by the second most effective method, and end with the least effective method. These recommendations are based upon large community interventions which demonstrated that counseling from most to least effective and removing financial and transportation barriers to LARCs increase uptake of more effective methods and reduce subsequent pregnancies. ${ }^{6,7}$ Long acting reversible contraceptives (LARCs) have emerged in recent years as first line options for teens due to their high efficacy and safety. In many ways, LARCs are ideal for teens as they offer a high level of privacy (once they are placed, there is no need for frequent clinic visits or trips to the pharmacy), little to no challenges to adherence, and rapid return to fertility once removed. Fewer contraindications to use exist with these methods. The American Academy of Pediatrics (AAP), Society for Adolescent Health and Medicine (SAHM) and the American College of Obstetrics and Gynecology (ACOG) recommend these contraceptives as first line options for teens. ${ }^{12,34,35}$

The SPR recommends reducing barriers to contraception, such as cost, transportation, and the need for pelvic exams. This recommendation is especially relevant to teens. Risk of current pregnancy should be assessed per SPR guidance, ${ }^{11}$ and if low risk or switching 
from another form of contraception that was used reliably, contraception should be started at that visit. Urine pregnancy tests, STI testing, and physical examinations are usually not required to start contraception. If risk of pregnancy is unknown, all contraceptives other than intrauterine devices and systems can be started and pose limited risks to early pregnancy. ${ }^{36,37}$ If contraception is started and pregnancy risk cannot be assessed at time of initiation, emergency contraception offered, and a urine pregnancy test should be performed 2-4 weeks after starting.

A common instance when it is hard to assess risk of pregnancy is when your patient has not been on reliable contraption and engaged in sex 1-2 weeks prior to the appointment (depending on the type of pregnancy test used). Emergency contraception should be strongly considered in this case. Levonorgestrel, ullipristal acetate and the copper IUD are all medications used for emergency contraception. Detailed guidance on prescription and use is readily accessible on multiple websites online, including that of the World Health Organization (See Box 2) ${ }^{38}$ Data support the advanced provision of levonorgestrel and ullipristal acetate for adolescents using no contraception or a less effective forms of contraception. ${ }^{39,40}$

Adolescents and young adults have the highest rates of STIs. Thus condoms should be encouraged to be used in combination with all other methods. Alone, condoms as typically used are moderately effective for contraception, but are the only method that prevents sexually transmitted infection. An additional point to emphasize is the fact that together with a more effective hormonal or LARC method, they can boost contraception effectiveness to near $100 \%$.

\section{Contraception Methods}

All contraceptive methods available to adults are available to teens, with the exception of sterilization. Contraceptives vary by the presence and type of hormones and duration of action. LARCs are first line options for teens and encompass the implant and intrauterine devices. This review is organized in the same manner as counseling, in order of most to least effective. An overview of each method is provided below, with links to prescribing 
instructions and online resources (see Box 2). While contraception is very safe overall, some carry unacceptable risks in those with certain medical conditions; specific evidence based medical eligibility for criteria for contraception is easily accessible through the World Health Organization and Centers for Disease Control and Prevention websites (see Box 2).

\section{Hormonal Implants}

Hormonal implants are highly effective forms of contraception containing a progestin. In comparison to earlier implants with five rods, the implants available today are single rod devices containing etonorgestrel or double rod devices containing levonorgestrel. They are placed subdermally in the upper arm. The etonorgestrel rod is effective up to 3 years while the levonorestrel double rod is effective up to 5 years. Both devices have typical use effectiveness rates over $99 \%$. Implants prevent pregnancy by suppressing ovulation and thickening cervical mucous.

Implants can be easily placed. Once placed, there are few barriers that exist affecting compliance (ex. Clinic visits, patient responsibility at home). Placement is a welltolerated, fast, and simple procedure that is not overly intimidating: with or without local anesthesia, a specially designed inserter slides the implant under the skin. The patient's only responsibility for effective use is getting it replaced on time, when the 3 or 5 years have expired. They offer a high degree of privacy - although they can be easily palpated in the upper arm when skin is held taught, they are relatively invisible under the skin with little to no scarring at their insertion site. Training is easily obtained and implants can be placed by pediatricians and other primary care providers during a regular office visit.

Implants have relatively few serious side effects and risks. Although implants suppress ovulation, follicular suppression does not occur and normal estrogen levels are maintained. Absolute contraindications are few and exist in conditions uncommonly seen in teens: Breast cancers. Caution should be used when prescribing to patients with systemic lupus erythematous, advanced liver disease, or unexplained vaginal bleeding. Disruption of regular menses is the most common side effect and can lead to frequent and 
irregular bleeding. Such bleeding is generally not harmful and does not lead to anemia however, can affect quality of life and desire for continuation of the method. Advance counseling of this side effect, having yourself available to the patient when it happens for reassurance, and trial of NSAIDs or estrogens can help support patients who have undesired bleeding. This side effect renders the implant less reliable for complete menstrual suppression however, its few contraindications and side effects make it a desirable form of contraception for medically complex patients as well as teens desiring very highly effective contraception.

\section{Intrauterine Devices (IUDs)}

Another good option for teens desiring highly effective contraception is intrauterine contraception. Many design changes have occurred over the years in this group of contraceptives. Today's T-shaped IUDs and IUSs are very safe, easy to insert, and more effective than prior versions.

Myths around infection and IUDs still exist today and should be explained and counseled on. IUDs increase the risk of pelvic infection only in the first month after insertion; afterwards, an individual's risk of pelvic infection returns to baseline. While adolescents and young adults have the highest age-specific rates of sexually transmitted infections, outside of the first month, IUDs do not increase that risk. ${ }^{41}$ It is recommended that IUDs and IUSs are not placed when there is an acute pelvic infection. However, there is no need to have a documented negative test prior to insertion. ${ }^{11}$ If evidence for infection exists during the pelvic exam performed immediately prior to placement (such as purulent cervical discharge or uterine tenderness), the procedure should be delayed until testing and treatment has been completed. If the exam is normal, testing for Chlamyidia trachomonitas or Neiserria gonorrheae can be done during placement and these asymptomatic infections treated routinely. If the adolescent with an IUD develops pelvic inflammatory disease, standard treatment should be implemented and the IUD removed only if the adolescent fails standard of care treatment. ${ }^{42}$ The other contraindications relevant to teen are uterine anomalies (e.g. accessory uterine horns) that may affect their ability to host a device. Some worry about younger adolescents having an adequate 
uterine size and favor smaller devices; However progestin containing IUDs have been used extensively in adolescents with disabilities, including very young and physically small adolescents. ${ }^{43,44}$ This clinical experience demonstrates that the adolescent with normal anatomy can tolerate all of the devices on the market, bimanual examination at the time of placement is recommended to assess uterine size and the presence of anomalies.

Two forms of IUDs are on the market in the US and Europe: the copper IUD and progestin containing IUD. Once place, progestin IUDs are effective between 3-5 years (depending on the specific device) and the copper IUD is effective up to 12 years. All have a greater than $99 \%$ effectiveness and are similar in design and placement procedure.

Progestin IUDs: : The progestin IUDs are levonorgestrel releasing devices that work primarily locally: The progestin thickens cervical mucous and induce endometrial atrophy. They may suppress ovulation (although, most continue to ovulate). ${ }^{44}$ Progestin IUDs vary by the amount of hormone, length of time they are effective, and size. Differences in the amount of hormone create differences in menstrual suppression rates. Most individuals on any of the progestin IUDs experience lighter periods, and the higher the amount of levonorgestrel, the more likely amenorrhea will result. Progestin IUDs are great options for teens with a history of dysmenorrhea, menorrhagia, or desiring menstrual suppression. ${ }^{32}$ They have been used extensively to induce amenorrhea for adolescents with mobility-related and cognitive disabilities because of difficulties related to hygiene. ${ }^{43}$

The non-hormonal copper-containing IUD induces a sterile inflammatory response in the uterus, rendering it inhospitable to sperm. Additionally, the copper IUD is the most effective form of emergency contraception and can be used up to 10 days after unprotected sex, but most often recommended within 5 days. ${ }^{46}$ The main side effect is effects on the menstrual cycle. Unlike progestin IUDs, regular ovulation and menses continue when on the copper IUD. However, bleeding can be heavier and accompanied by more cramping than an individual's natural periods. Because the copper IUD has no 
hormones, it is the safest option for teens with significant histories of thromboembolic disease or serious complex health conditions that make pregnancy dangerous. ${ }^{11}$

IUDs are inserted in the office during a pelvic exam. The pelvic exam is necessary in order to assess uterine size and, can be done as part of placement. Many teens have never had a pelvic exam and find the prospect intimidating. Taking time to describe the procedure and answer questions, emphasizing it is more awkward than painful, and reminding your patient to keep in mind the high effectiveness of these devices and minimal effort required once placed are all important points to emphasize. If family or friends are successfully using an IUD, you can suggest the adolescent ask that person about what placement is like. The website Bedsider.org features videos of young women talking about their experiences with the devices. Cervical blocks and non-steroidal antiinflammatory drugs (NSAIDs) have little evidence to support their use in improving the

placement experience in adults; $;{ }^{47}$ however, NSAIDs can be offered prior to the procedure to help with post procedure cramping.

Expulsion and irregular bleeding are the two main side effects of these methods. Expulsion is when the uterus contracts to push the device out of the uterus - either completely (into the vagina) or partially (into the cervical canal). Expulsion rates vary among studies but, overall are very low. Patients should be instructed to call if they experience unexplained cramping or bleeding. If an expulsion is suspected, providers can image with a pelvic ultrasound.

\section{Progestin Injectable Contraception}

The three progestin-only injectable contraceptives are depo medroxyprogesterone acetate (DMPA) intramuscular injection, the DMPA subcutaneous injection, and norethisterone enanthate (NET-EN). Only the two DMPA formulations are available in the United States; NET-EN is available in other countries. The subcutaneous DMPA injection contains slightly less hormone and can be administered at home. Effectiveness is not as high as LARCs but, fairly good at $94 \%$ with typical use (it is more than $99 \%$ with perfect 
use) ${ }^{45}$ The injectable contraceptives work by suppressing ovulation and follicular development. The resultant lower estrogen state leads to thinning of the endometrium and inhibits endometrial proliferation.

Effectiveness can be affected by a teen's ability to see a provider at the required injection interval ( 3 months for DMPA and 2 months for NET-EN). This is a significant point to consider as teens have many barriers to health care such as transportation, lack of teen friendly clinic policies, confidentiality concerns, and continuous health care (a stable clinic or stable insurance). Frequent visits can be difficult for busy teens in school, working, participating in sports, or involved in extracurricular activities. Frequent visits can often diminish the ability to have privacy from family with regards to contraception; however, because it is an injection, if an individual can come to their appointment independently, there is no evidence of being on contraception otherwise.

Individuals on progestin injectables have high rates of amenorrhea and, of all of the contraceptives, it is among the most reliable contraceptives for menstrual suppression. Amenorrhea usually does not happen immediately; instead, women have fewer days of bleeding or spotting with time. Because of its strong ovarian suppression, DMPA can be helpful in teens who have menstrual related symptoms (such as severe dysmenorrhea or endometriois, vomiting, some forms of headaches, catamenial seizures, or behavioral concerns). It can be used while breastfeeding. Like the implant and IUDs, it does not contain estrogen, and has fewer contraindications than combined hormonal contraceptives.

Progestin injectables have few absolute contraindications relevant to teens. However, it has several side effects of concern to teens. Of all contraceptives, DMPA is the only one with evidence of weight gain. ${ }^{48}$ Assessing current diet and providing dietary counseling is very important when starting DMPA in overweight teens. A second concerning side effect is decreased bone mineral density (BMD). ${ }^{49,50}$ This is due to the relative hypoestrogenic state DMPA creates. The decrease in BMD appears reversible once the 
medication is stopped, ${ }^{51,52}$ but long term effects in late adulthood are unknown at this time. Teens with risk factors for lower BMD, such as low body mass indexes, chronic corticosteroid use, and immobility, should be counseled on this and protective bone health activities encouraged such as weight bearing exercise and consuming adequate dietary calcium. ${ }^{52}$ Exercise should be encouraged for both weight gain and decreased bone mineral density (BMD). Other side effects of DMPA are rarer but, represent conditions with high prevalence in teens. Depression, headaches, and acne can be worsened. DMPA can also lower sex drive.

Despite its side effect profile, progestin injections are a well-known and highly effective forms of contraception that requires little compliance other than keeping appointments. Counseling should address negative side effects, but also highlight it's high effectiveness, ease of administration, and desirable side effects (amenorrhea).

\section{Combined Hormonal Contraceptives (CHCs)}

CHCs contain both estrogen and progestins and come in 4 different modes of administration: oral, transdermal, transvaginal, and the combined contraceptive injection. The combined contraceptive injection is not available in the US. COCs, the transdermal patch, and the vaginal ring have a similar effectiveness of approximately $91 \%$ with typical use. ${ }^{53}$ Side effects and risks are also similar. The primary mode of action for CHCs is suppression of ovulation, through lowering pituitary hormone release. While progestin only contraceptives are safe to use while breast feeding, CHCs are not.

Used traditionally, these medications have 4 week cycles of three weeks of ovarian suppression via hormonal pills followed by one week of hormone withdrawal and subsequent menses via placebo pills. All can also be used continuously by not taking the placebo week. Unlike the progestin only contraceptives, when used traditionally, a regular pattern of menses is maintained. CHCs can be easily switched from one to another or used continuously. With combined oral contraceptive pills (COC), the prescriber can change the dose of estrogen and formulation of progestin estrogen 
increased or decreased or progestin changed to "personalize" this medication to an individual's side effects or desired level of menstrual suppression.

CHCs have been used more than any other contraceptive to manage medical conditions. ${ }^{54}$ They lessen menstrual blood loss through lighter, shorter periods. They also can significantly decrease or stop cramps. If periods remain heavy or painful with monthly cycles, extending cycles to every 3 months or more lets individuals experience these symptoms less often or schedule periods for a time when periods won't disrupt important life events. In cases of menorrhagia, multiple pills or patches can be used for brief periods of time to give a larger dose of estrogen and slow or stop menses. For individuals with endometriosis, menstrual cycle syndromes or symptom flares can be treated with continuously administered CHCs. ${ }^{54}$

CHCs also decrease circulating free testosterone by increasing levels of sex hormone binding globulin. This effect is why CHCs are used to treat acne and mild cases of hirsuitism. Lowering circulating testosterone with CHCs is also used in individuals with polycystic ovarian syndrome, improving androgenic signs and regulating periods.

Although CHCs have relatively more contraindications than progestin only contraceptives, they are still a safe choice for most adolescents. For adolescents with chronic medical conditions, providers will need to consult the MEC and, in some cases, the relevant pediatric subspecialist. CHCs are contraindicated in adolescents with a personal history of thromboembolic disease or a thrombogenic mutation because of an increased risk of thromboembolism. CHCs are also contraindicated for adolescents with migraine headaches who experience a true aura due to an increased risk of stroke. CHCs should be used with caution in controlled hypertension and are contraindicated in uncontrolled hypertension. ${ }^{11}$

Many adolescents with medical problems have congenital conditions, and because the contraindication data come from studies of adult conditions, the MEC can be difficult to apply. For example, CHCs may or may not be appropriate for adolescents with a history 
of congenital heart disease. Estrogen is contraindicated in severe valvular disease. For some adolescents with milder forms of congenital heart disease with definitive repairs, such as those with simple atrial or ventricular septal defects, CHCs may be safe.

However, for those whose anomalies and repairs have resulted in valvular dysfunction, CHCs should not be used. A full list of contraindications and cautions can be found in the WHO MEC. ${ }^{10}$

CHC counseling should screen for the contraindications, review risks, side effects, and benefits, and assist the adolescent in making a personal decision. Some will want to avoid side effects; for others, particularly those with menstrual symptoms, CHCs can dramatically improve well-being. Signs of thromboembolic disease should be fully explained as well as side effects such as breast tenderness and nausea. Compliance factors, such as ability to take the medication regularly (daily, weekly or monthly per method) and filling the prescription at the pharmacy, should be discussed. Utilizing cell phone alarms, working administration into a daily routine, and parental involvement are all tools to improve compliance.

\section{Contraception Provision in Practice}

Because there are many LARC and hormonal methods available, and interviewing requires time to build rapport and establish confidentiality, the provision of effective contraception to adolescents can appear a daunting task. However, pediatric providers occupy a place of trust with families and adolescents, and are often the only point for adolescent to access family planning. Additionally, many adolescents are familiar with contraception through use by family members or friends, educational programs, and online resources. By assessing adolescents' baseline knowledge and experiences (an important part of $\mathrm{MI}$ ), and keeping the following key points in mind, pediatricians can incorporated LARCs and hormonal contraceptives into their pediatric practice.

- Make clinic space teen friendly: Have separate waiting areas for teens with relevant health information available including information on contraception and confidentiality. 
- Begin sexuality discussions during early adolescence. This screens for early risk behavior, signals to adolescents that you are willing to talk about difficult topics, and trains parents both to communicate with their teens about contraception and to allow adolescents the privacy and responsibility of talking to a provider on their own.

- While contraceptives are very safe for most patients, international and US-based resources allow providers to quickly identify contraindications and risks for medically complex adolescents.

- Counsel in order of most to least effective methods, discussing side effects in light of both contraceptive and medical benefits.

- Be available after prescription to address side effects, compliance, and satisfaction.

- Adolescents whose providers are willing to address difficult topics such as pregnancy prevention and contraception are more engaged in their own health care (Brown and Wissow). Counseling and providing effective contraception not only prevents unintended pregnancy, but can enhance your adolescent patient's journey through a successful adolescence 


\section{$\underline{\text { References }}$}

1. World Health Organzation. Adolescent Pregnancy. 9 2014. 1422017

$<$ http://www.who.int/maternal_child_adolescent/topics/maternal/adolescent_pregnan $\mathrm{cy} / \mathrm{en} / \mathrm{P}$.

2. World Health Organization; . Early marriages, adolescent and young pregnancies.

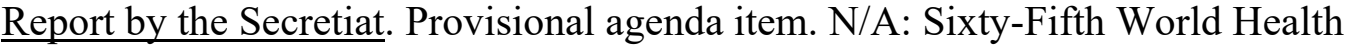
Organization, 2012.

3. Singh, S, G Sedgh and R Hussain. "Unintended pregnancy: worldwide levels, trends and outcomes." Studies in Family Planning 41.4 (2010): 241-250.

4. Kost, K and I Maddow-Zimet. Teenage Pregnancies, Births and Adoptions: National and State Trends and Trends by Race and Ethnicity. New York: Guttmacher Institute, 2016.

5. Perper, K, K Peterson and J Mangrove. "Diploma Attainment among Teen Mothers." Child Trends 4 (2010).

6. Secura, G, et al. "Provision of no-cost, long-acting contraception and teenage pregnancy." The New England Journal of Medicine 371.12 (2014): 1316-1323.

7. Bredsel, D. Colarado's teen birth rate continues to plummet. 15102015.742017 $<$ https://www.colorado.gov/pacific/cdphe/news/teenbirthrate $>$.

8. Finer, L B and M R Zolna. "Declines in unintended pregnancy in the United States, 2008-2011." New England Journal of Medicine 374.9 (2016): 843-852.

9. Lindberg, Laura, John Santelli and Shelia Desai. "Understanding the Decline in Adolescent Fertility in the United States, 2007-2012." Journal of Adolescent Health 59 (2016): 577-583.

10. World Health Organization. Medical Eligibility Criteria for Contraception Use Fifth Edition. 2015. Geneva: World Health Organization.

11. Curtis, K M, N K Tepper and T C Jallaoui. "U.S. Medical Eligibility Criteria for Contraceptive Use, 2016." MMWR Recommendations Report 2016: 1-104.

12. Curtis, K M, et al. "U.S. Selected Practice Recommendations for Contraceptive Use, 2016." MMWR 2972016.

13. Ott, M Sucato, G. "Contraception for Adolescents." Pediatrics 134.4 (2014). 
14. Ford, C, A English and G Sigman. "Confidential Helath Care for Adolescents: position paper for the society for adolescent medicine." Journal of Adolescent Health 35.2 (2004): 160-167.

15. Ford, C A, et al. "Influence of physician confidentiality assurances on adolescents' willingness to discluse information and seek future health care. A randomized control trial." JAMA 288.12 (1997): 1029-1034.

16. Lehrer, J A, et al. "Forgone health care among U.S. adolescents: associations between risk characteristics and confidentiality concern." Journal of Adolescent Health 40.3 (2007): 218-226.

17. Reddy, D M, R Fleming and C Swain. "Effect of mandatory parental notification on adolescen girls' use of sexual health care services." JAMA 288.6 (2002): 710-714.

18. Brown, J D and L S Wissow. "Discussion of senstive health topics with youth during primary care visits: relationship to youth perceptions of care." Journal of Adolescent Health 44.1 (2009): 48-54.

19. Jones, R K, et al. "Adolescents' reports of parental knowledge of adolescents' use of sexual health services and their reactions to mandated parental notifcaiton for prescription contraception." JAMA 293.3 (2005): 340-348.

20. Part, K, et al. "Teenagae pregnancies in the European Untion in the context of legislation and youth sexual and reproductive health services." Acta obestetricia et gynecologica Scandinavica 92.12 (2013): 1395-1406.

21. American Academy of Pediatrics, Committee on Adolescence. "Policy Statement: achieving quality health services for adolescents." Pediatrics 121.6 (2008): 12631270.

22. American College of Obestetricians and Gynecologists. Guidelines for Adolescent Health Care. Washington, DC: American College of Obstetricians and Gynecologists, 2011.

23. European Association of Paediatrics. "Adolescent Sexual Health for Paediatric Primary Care: Recommendations of the Adolescents Health Care Working Group EAP 2009." 2015. Adolescent Health and Wellness. 142017 $<$ http://eapaediatrics.eu/wpcontent/uploads/2015/12/Recomendations_AdolescSexualHealth4_12_09B.pdf $>$. 
24. United Nations Committee on the Rights of the Child. General Comment No. 4: Adolescent Health and Development. New York (NY): United Nations, 2003.

25. Elliot C, Martino S, et al. "Beyond the "Big Talk": The Roles of Breadth and Repetition in Parent Child Communcation About Sexual Topics." Pediatrics 121.3 (2008).

26. Deptula, DP, Henry, DB and Schoeny, ME. "How can parents make a difference? Longitudinal associations with adolescent sexual behavior. ." Journal of family psychology 24.6 (2012): 731-739.

27. Macdowall, W, Jones, KG and Tanton, C. "Associations between source of information about sex and sexual health outcomes in Britain: findings from teh third National Survey of Sexual Attitudes and Lifestyles (NATSAL-3)." British Medical Journal 5.3 (2015): e007837.

28. Martinez, G M and J C Abma. "Sexual Activity, Contraceptive Use, and Childbearing of Teenagers Aged 15-19 in the United States." July 2015. Centers for Disease Control. 1222017 $<$ https://www.cdc.gov/nchs/products/databriefs/db209.htm>.

29. National Guidelines Task Force. "Guidelines for Comprehensive Sexuality Education: Kindergarten through 12th Grade, 3rd Edition." 2004. Sexuality Information and Education Counil of the United States. 142014

30. Barnet, B, et al. "Motivational intervention to reduce rapid subsequent births to adolescent mothers: A community-based randomized trial." Annals of Family Medicine 7.5 (2009): 436-445.

31. Centers for Disease Control and Prevention. 2015 Sexually Transmitted Disease Treatment Guidelines: Clinical Prevention Guidance. 2015. 1222017 $<$ https://www.cdc.gov/std/tg2015/clinical.htm>.

32. Sucato, G S, et al. "Transdermal contraception as a model for adolescent use of new methods." Journal of Adolescent Health 49.4 (2011): 357-362.

33. Ott, M A, et al. "The trade-off between hormonal contraceptives and condoms among adolescents." Perspectives on sexual and reproductive health 34.1 (2002): 614. 
34. The Society for Adolescent Health and Medicine. "Sexual and Reproductive Health Care: A Position Paper of the Society for Adolescent Health and Medicine." Journal of Adolescent Health 54.4 (2014): 491-496.

35. American College of Obstetricians and Gynecologists. "ACOG Strengthens LARC Recommendations." 2015. American College of Obstetricians and Gynecologists. 20 $122016<$ http://www.acog.org/About-ACOG/News-Room/NewsReleases/2015/ACOG-Strengthens-LARC-Recommendations>.

36. Pardthaisong, $\mathrm{T}$ and R Gray. "In utero exposure to steroid contraceptives and survival during infancy." American Journal of Epdemiology 134 (1991): 795-803.

37. Pardthaisong, T, C Yenchit and R Gray. "The long-term growth and development of children exposed to Depo-Provera during pregnancy of lactation." Contraception 45 (1992): 313-24.

38. World Health Organization. Emergency Contraception. Feb 2016. 742017

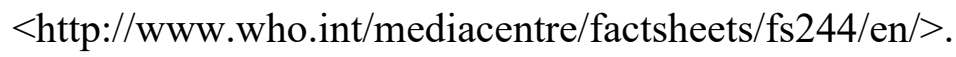

39. Raine, $T$, et al. "Emergency contraception: Advance provision in a young, high-risk clinic population." Obtetrics and Gynecology 96.1 (2000): 1-7.

40. Gold, M A, et al. "The effects of advance provision of emergency contraception on adolescent women's sexual and contraceptive behaviors." Journal of Pediatric and Adolescent Gynecology 17.2 (2004): 87-96.

41. Jatlaoui, T C, K B Simmons and K M Curtis. "The safety of intrauterine contraception initiation among women with current asymptomatic cervical infections or at increased risk of sexually transmitted infections." Contraception 94.6 (2016): 701-712.

42. Tepper, N K, et al. "Retention of intrauterine devices in women who acquire pelvic inflammatory disease: a systemic review." Contraception 87.5 (2013): 655-60.

43. Quint, E H and R F O'Brien. "Menstrual Management for Adolescents with Disabilities." Pediatrics 138.1 (2016).

44. Quint, E H. "Menstrual and reproductive issues in adolescents with physical and developmental disabilities." Obestrtics and Gynecology 124.2 Pt 1 (2014): 367-375 
45. Barbosa, I, et al. "Ovarian function during use of the levo-norgestrel IUD." Contraception 42.1 (2000): 51-66.

46. Cleland, K, et al. "The efficacy of intrauterine devices for emergency contraception: a systemic review of 35 years of experience." Human reproduction 27.7 (2012): 1994-2000.

47. Allen, R H, et al. Interventions for pain with intrauterine device insertion. The Cochrane LIbrary. 2009, n.d.

48. Lopez, L M, et al. "Progestin-only contraceptives: effects on weight." The Cochrane database of systemic reviews, 2013.

49. Cromer, B A, et al. "Bone mineral density in adolescent females using injectible or oral contraceptives: a 24-month prospective study." Fertility and Sterilization 90.6 (2008): 2060-2067.

50. Berenson, A B, et al. "Effects of depot medroxyprogesterone acetate and 20microgram oral contraceptives on bone mineral denisty." Obstetrics and Gynecology 112.4 (2008): 788-799.

51. Kaunitz, A M, R Arias and M McClung. "Bone density recovery after depot medroxyprogesterone use." Contraception 77.2 (2008): 67-76.

52. Harel, Z, et al. "Inadequate vitamin D status in adolescents with substantial bone mineral density loss during the use of depot medroxyprogesterone acetate injectable contraceptive: a pilot study." Journal of Pediatric and Adolescent Gynecology 23.4 (2010): 209-214.

53. Trussell, J. "Contraceptive efficacy." Hatcher, R, et al. Contraceptive Technology 20th revised edition. Atlanta: Ardent Media, Inc., 2011. 779-863.

54. Kantartzis, K L and G S Sucato. "Menstrual suppression in the adolescent." Journal of Pediatric and Adolescent Gynecology 26.3 (2013): 132-137. 


\section{Box 1. Key Questions for Birth Control Counseling}

- How old do you think you will be when you start having sex? Why that age?

- How old do you want to be when you start having children? How will we get there?

- What have your parents told you about sex and what do you think about that?

- Tell me some things you need to be careful about if you are having sex? How will you do this?

- Have you been in a romantic relationship before? Tell me about that person. Was sex part of your relationship? Did you talk about sex with them and what did you talk about?

- Tell me what you know about birth control and what you like/don't like about it. 


\section{Box 2. Contraception Resources Available to Providers}

$\begin{array}{ll}\text { Resource } & \text { Available at: } \\ \text { World Health Organization } & \\ \text { Medical Eligibility Criteria 2016 } & \frac{\text { http://www.who.int/reproductivehealth/pu }}{\text { blications/family planning/MEC-5/en/ }} \\ \text { Selected Practice Recommendations 2016 } & \text { http://www.who.int/reproductivehealth/p } \\ & \text { ublications/family_planning/SPR-3/en/ } \\ \text { Making Health Services Adolescent } & \text { http://apps.who.int/iris/bitstream/10665 } \\ \text { Friendly } & \text { /75217/1/9789241503594_eng.pdf } \\ \text { Emergency Contraception Instructions } & \text { http://www.who.int/mediacentre/factsheet } \\ & s / f s 244 / \text { en/ }\end{array}$

\section{U.S. Centers for Disease Control and Prevention}

U.S. Medical Eligibility Criteria 2016*

U.S. Selected Practice Recommendations 2016 *

European Association of Paediatrics

Guidance for reproductive health care in primary care

\section{Association of Reproductive Health Professionals}

Clinical guidance and patient resources on birth control selection Contraceptive Technology

Clinical guidance and resources for providers

United Nations Population Fund

The Rights to Contraceptive Information and Services for Women and Adolescents

Knowledge for Health (K4Health)

Toolkits for family planning services and adolescent-friendly services. http://eapaediatrics.eu/wpcontent/uploads/2015/12/Recomendations AdolescSexualHealth4 12 09B.pdf

https://www.cdc.gov/reproductivehealth/ contraception/mmwr/mec/summary.html https://www.cdc.gov/reproductivehealth/ contraception/mmwr/spr/summary.html

http://www.arhp.org/topics/adolescent-

http://www.contraceptivetechnology.org/

http://www.unfpa.org/resources/rightscontraceptive-information-and-serviceswomen-and-adolescents

http://www.unfpa.org/resources/rightscontraceptive-information-and-serviceswomen-and-adolescents health 
* Also available as a smart phone app

\section{Box 3. Contraception Snap Shot}

\begin{tabular}{|c|c|c|}
\hline Method & Common Benefits & Common Drawbacks \\
\hline $\begin{array}{l}\text { Contraceptive } \\
\text { Implant }\end{array}$ & $\begin{array}{l}+ \text { Private } \\
+ \text { Very easy to use } \\
+ \text { Can lighten periods } \\
+ \text { Safe for almost everyone } \\
+ \text { Highly effective }\end{array}$ & $\begin{array}{l}\text { - Spotting or irregular } \\
\text { menstrual bleeding }\end{array}$ \\
\hline Copper IUD & $\begin{array}{l}+ \text { Private } \\
+ \text { Very easy to use } \\
+ \text { Non-hormonal, safe for most } \\
+ \text { Emergency contraception } \\
+ \text { Highly effective }\end{array}$ & $\begin{array}{l}\text { - Heavier, crampier periods } \\
\text { - Small risk of expulsion }\end{array}$ \\
\hline Progestin IUD & $\begin{array}{l}+ \text { Private } \\
+ \text { Very easy to use } \\
+ \text { Menstrual suppression } \\
+ \text { Treatment of endometriosis } \\
+ \text { Highly effective }\end{array}$ & $\begin{array}{l}\text { - Spotting or irregular } \\
\text { menstrual bleeding } \\
\text { - Small risk of expulsion }\end{array}$ \\
\hline $\begin{array}{l}\text { Progestin } \\
\text { Injectable }\end{array}$ & $\begin{array}{l}+ \text { Private } \\
+ \text { Easy to use } \\
+ \text { Menstrual suppression } \\
+ \text { Treatment cyclic menstrual } \\
\quad \text { disorders and endometriosis }\end{array}$ & $\begin{array}{l}\text { - Administered every } 3 \text { months } \\
\text { - Weight gain } \\
\text { - Lower bone density } \\
\text { - Might worsen depression or } \\
\text { acne }\end{array}$ \\
\hline $\begin{array}{l}\text { Combined } \\
\text { Hormonal } \\
\text { Methods (Pill, } \\
\text { Patch, Ring, } \\
\text { Injectable) }\end{array}$ & $\begin{array}{l}+ \text { Lighter, less crampy periods } \\
+ \text { Treat acute menorrhagia } \\
+ \text { Menstrual suppression } \\
+ \text { Treatment for PCOS } \\
+ \text { Helps acne and hirsuitism } \\
+ \text { Treatment cyclic menstrual } \\
\quad \text { disorders and endometriosis }\end{array}$ & $\begin{array}{l}\text { - More contraindications due } \\
\text { to estrogen component } \\
\text { - Risk of thromboembolism } \\
\text { - Estrogen-related side effects, } \\
\text { such as nausea and breast } \\
\text { tenderness } \\
\text { - Home administration (daily, } \\
\text { weekly or monthly) and } \\
\text { ability to refill at a pharmacy }\end{array}$ \\
\hline
\end{tabular}


Box 4: Example English-language Online Resources for Adolescents (not a complete list)

\begin{tabular}{|ll|}
\hline Resource & $\begin{array}{l}\text { Description } \\
\text { A birth control information network for adolescents and } \\
\text { young adults, sponsored by the USA National Campaign to } \\
\text { Prevent Teen and Unplanned Pregnancy. }\end{array}$ \\
Stayteen.org & $\begin{array}{l}\text { A sexual health site for adolescents that includes } \\
\text { contraceptives as well as information on topics such as } \\
\text { health relationships and dating violence; sponsored by the } \\
\text { USA National Campaign to Prevent Teen and Unplanned } \\
\text { Pregnancy. }\end{array}$ \\
DexEtc.org & $\begin{array}{l}\text { A sexuality web site written by and for adolescents; } \\
\text { includes contraceptives as well as nuanced information on } \\
\text { gender and sexuality; sponsored by the USA organization, } \\
\text { Answer, based at Rutgers University. }\end{array}$ \\
BubjectMatter.org & $\begin{array}{l}\text { A sexual health information website and mobile platform } \\
\text { for Nigerian adolescents and young adults, sponsored by } \\
\text { Planned Parenthood Global, the Nigerian government, and } \\
\text { the United Nations Population Fund. }\end{array}$ \\
& $\begin{array}{l}\text { A sexual health website for young people under 25 years in } \\
\text { the United Kingdom, with information and links to service } \\
\text { sites, sponsored by Brook. Includes a 24/7 Ask tool. }\end{array}$ \\
&
\end{tabular}

